\title{
The BAD-LAD split: Secondary /æ/-lengthening in Southern Standard British English
}

\author{
Thomas Kettig*
}

\begin{abstract}
Descriptions of the Received Pronunciation (RP) and Southern Standard British English (SSBE) have previously commented on vowel lengthening in certain words such as bad and glad as opposed to shorter lad and pad. This paper comprises the first thorough description of the conditioning of /æ/ duration in twenty-one young native SSBE speakers, finding inconclusive evidence for a lexically specified split but significant general lengthening effects of postvocalic $/ \mathrm{g} /$ and $/ \mathrm{d} /$; this secondary loe/-lengthening is discussed in reference to phonological analyses of the TRAP-BATH split (primary /oe/-lengthening) and previously established descriptions of coarticulatory segmental effects on vowel length.
\end{abstract}

Keywords. Southern Standard British English (SSBE); the Received Pronunciation (RP); vowel duration; secondary /æ/-lengthening

1. Secondary /a/-lengthening: history and previous reports. In Early Modern English varieties spoken in $17^{\text {th }}-18^{\text {th }}$ century southern England, the Middle English short-/a/ vowel (TRAP) began to lengthen to /a:/ in some words. This lengthening manifested itself initially as allophonic phonetic variation conditioned by the following consonant: /a/ preceding tautosyllabic voiceless fricatives (e.g. bath, staff, pass) were the first to become /a:/, followed by lengthening preceding nasal + fricative clusters (e.g. dance) and nasal + voiceless stop clusters (e.g. can't) (Wells 1982). This long BATH vowel - eventually merged completely with the long PALM class changed in quality, producing the backer, more rounded /a:/ of England's $20^{\text {th }}$ century acrolectal Received Pronunciation (RP) and its successor dialect, Southern Standard British English (SSBE). In addition to this primary /oe/-lengthening, known as the TRAP-BATH split, several $20^{\text {th }}$ century phonetic descriptions of RP and SSBE have noted lengthening of the short-/æ/ (TRAP) vowel in an ill-defined subset of words, especially those containing postvocalic /d/. Such secondary /ae/-lengthening is the subject of this study.

Jones (1972 [1918]) reported in An Outline of English Phonetics that RP and the dialect of many Southern English people had a 'short' vowel in the words lad, cat, lamp, and pad but an optionally 'long' vowel in glad, bag, man, and jam. He singled out adjectives ending in - $d$ such as bad and sad as being especially prone to lengthening, and also mentioned back and that as being lengthened by many people, despite having voiceless coda consonants.

Wells (1982:288) described this phenomenon as "marginally contrastive long /æ:/", pointing particularly to bad, glad, clad, and sad as prototypically 'long' /æ/ words and cad, dad, fad, and pad as 'short' ones; he thought it "rare to find contrastive length in environments other than that of a following /d/", with /æ/ before voiced consonants tending to lengthen. As an example of a potential minimal pair, he cited the vowel in madder (more mad) as possibly longer than madder (plant that produces red dye) due to the former being bimorphemic with an inflectional ending. He cautioned that not all speakers in Southern England had this length distinction in their speech.

Beyond these fairly general descriptions of /æ/-lengthening, Fudge (1977), a native RP speaker from Hampshire, recorded his own dizzyingly complex lexical split between 'long' and 'short' /æ/. Among the patterns he observed in his own idiolect were that while the short vowel

\footnotetext{
* Acknowledgements especially to Francis Nolan and Adrian Leemann. Author: Thomas Kettig, Theoretical and Applied Linguistics, University of Cambridge; Linguistics, University of Hawai‘i at Mānoa (tkettig@gmail.com).
} 
could not be replaced by the long vowel, it seemed possible to shorten the vowel in 'long' words; monosyllables with voiceless stops in their coda (including nasal + voiceless stop clusters) were always short, in contrast to Jones's (1972 [1918]) suggestion of that and back lengthening; and all final voiced consonants and clusters seemed to permit both long and short $/ \mathfrak{a} /$ except for $/ \mathrm{y} /$, before which only short /æ/ was allowed. He noted not only a number of minimal pairs (e.g. drag verb vs. noun), but indeed several near-minimal triplets such as p[æ]nder vs. g[æ:]nder vs. sl[a:]nder.

In preparation for this study's phonetic experiment, informal open-ended elicitation sessions were carried out with two native SSBE speakers (both linguists) to verify previously described lengthening patterns as well as to find possible minimal pairs to test on later naïve subjects. Their own intuitions about words that would fall into 'long' or 'short' /æ/ categories are shown in Tables 1 and 2. The first linguist (Table 1) reported a difference in vowel duration between ram (long) and RAM (Random Access Memory, short), as well as mad (long) and MAD (MutuallyAssured Destruction, short), raising the possibility that minimal pairs may exist in which an etymologically longer-attested word contrasts in length with a newer word or acronym (cf. short trad mentioned by Wells 1982). The second linguist (Table 2) felt that strong preterits like ran, began, and rang were always short for him, in contrast to Linguist \#1's intuitions of long ran and began.

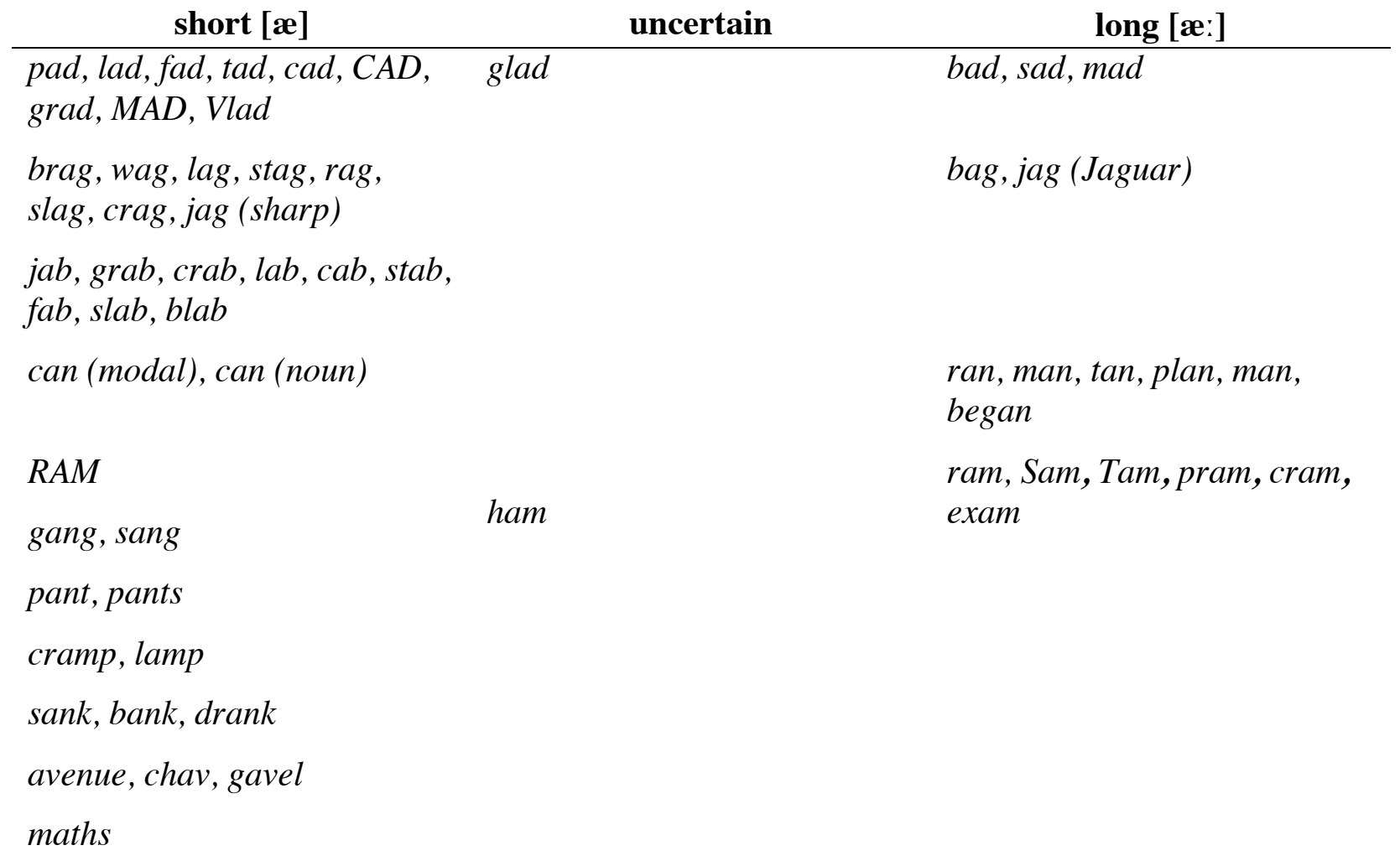

Table 1. Consultation with first native SSBE-speaking linguist (from Kent, born 1992) 


\begin{tabular}{|c|c|c|}
\hline short $[æ]$ & uncertain & long [æ:] \\
\hline $\begin{array}{l}\text { pad, lad, tad, Vlad, cad, CAD, } \\
\text { add }\end{array}$ & & bad, glad, sad \\
\hline tag, brag, sag & & bag \\
\hline $\begin{array}{l}\text { (door) jamb, dam, RAM, ram, } \\
\text { swam }\end{array}$ & & $\begin{array}{l}\text { Tam, jam (traffic, preserves), } \\
\text { damn }\end{array}$ \\
\hline \multicolumn{3}{|l|}{ ran, began } \\
\hline \multicolumn{3}{|l|}{ rang, sang } \\
\hline \multicolumn{3}{|l|}{ cant (song) } \\
\hline \multicolumn{3}{|l|}{ cash, cache, bash } \\
\hline badger & & badge \\
\hline
\end{tabular}

Table 2. Consultation with second native SSBE-speaking linguist (from Bristol, born 1989)

No previous descriptions have involved collecting data from a large number of idiolects or the actual measurement of vowel durations. In the absence of such sociophonetic data, the behavior of the TRAP vowel in SSBE remains unclear. The present study attempts to fill this gap and enable discussion on the phonological status of secondary /æ/-lengthening and possible historical parallels with primary /æ/-lengthening.

2. Phonetic Study Methodology. Twenty-one students at the University of Cambridge (aged $18-24,15$ women and 6 men) were recorded in a sound-attenuated booth using a Sennheiser ME 64 cardioid microphone connected to a Tascam HD-P2 compact flash audio recorder in 24 bit mono with a sample rate of $44.1 \mathrm{kHz}$. All participants were native speakers of SSBE, and as such exhibited fully split TRAP and BATH vowels. Vowel durations were measured and extracted using Praat (Boersma \& Weenink 2015).

This analysis only reports on aspects of lengthening in the set of monosyllabic words tested (81 distinct lexemes in total). Disyllabic words, apart from those investigated in Section 3.1 as minimal pairs, will be investigated further in future work. Carrier sentences were constructed with two clauses; the first clause established a context for the word, while the second clause, always following a comma, contained exactly five syllables preceding the target stressed syllable containing /æ/ in an attempt to control for pacing and focus. The target word always appeared sentence-finally; any effect of utterance-final lengthening or prominence would have affected all target words equally. Given the lack of previous phonetic studies investigating secondary /æ/lengthening in SSBE, the aim of this experiment was chiefly exploratory; besides four different tokens of $\mathrm{bad}$, glad, mad, and sad (used to determine that normalizing for utterance rate was unnecessary for this data), duration information was only collected for one token per word, per speaker.

A significant amount of breathy voice and/or preaspiration was found between the modal portion of the vowel and the following consonant across all speakers, primarily preceding voiceless fricatives in both monosyllabic and disyllabic words and voiceless stops in disyllabic words. Within the dataset analyzed here, sections of breathy voice and preaspiration are counted as part 
of total vowel duration; future work will focus on determining the prevalence and phonological status of breathy voice and preaspiration in SSBE, as it has not been previously reported as widespread.

3. Results. Since only one token per word per person was collected, save the four tokens each for $\mathrm{mad}$, bad, glad, and sad, traditional statistical methods cannot be used to establish which specific words are 'long' or 'short' within a single speaker. A linear mixed effects model run using R was instead employed; voicing and place and manner of articulation were entered (without interactions) into the model as fixed effects, with subject and word defined as random effects. Likelihood ratio tests were conducted between the full model including the effect in question against null models without the effect, outputting the $p$-values reported in Section 3.2.

3.1. MiNIMAL PAIRS. Native RP/SSBE-speaking linguists have previously asserted the existence of conventionally homophonous minimal pairs distinguished by /æ/ duration alone. However, none of the pairs targeted in this experiment were found to be consistently differentiated by vowel duration. In Figure 1, each word pair - such as adder (snake) vs. adder (calculator) - is represented by a vertical axis centered on a difference of 0 seconds.

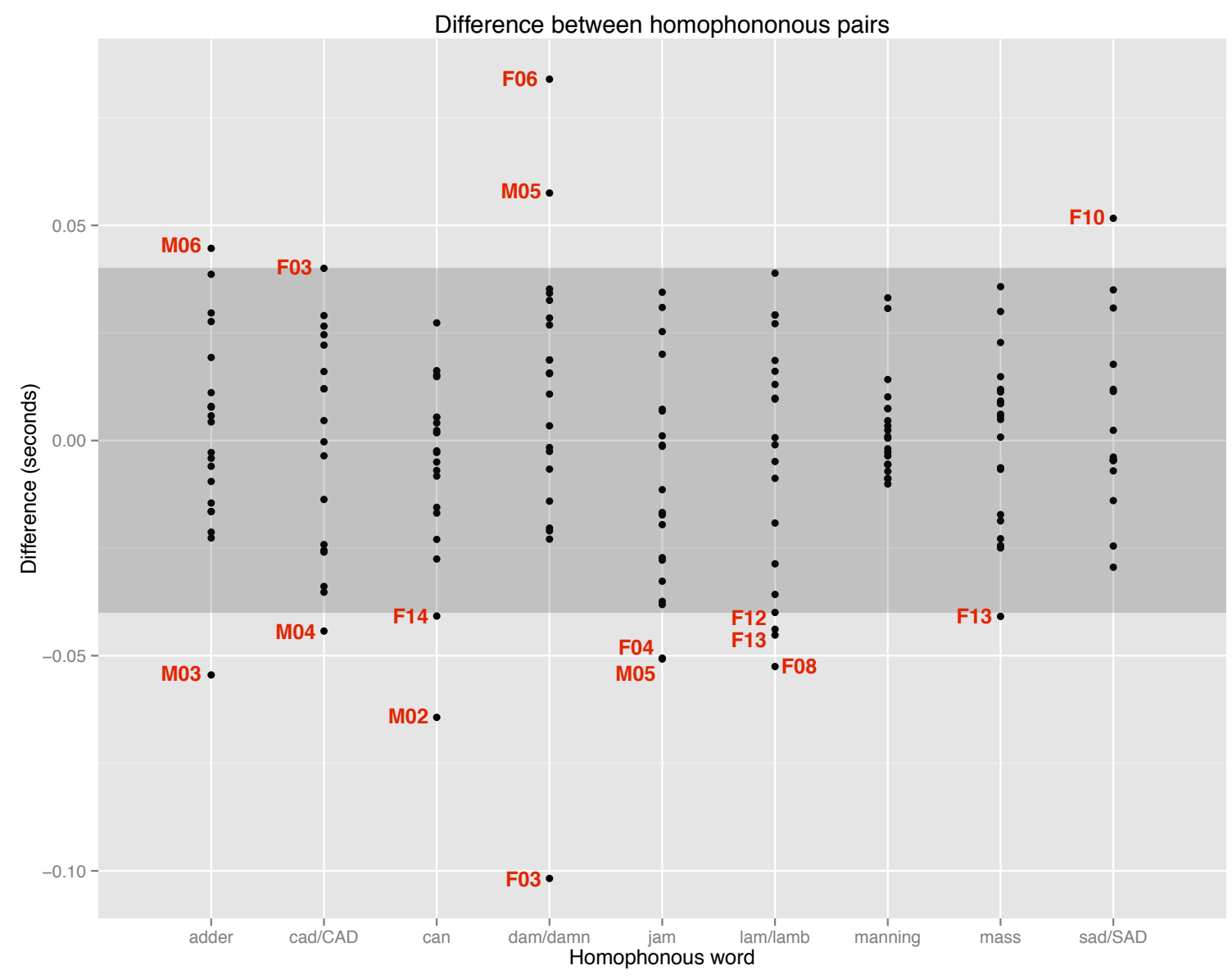

Figure 1. Difference in vowel duration between homophonous pairs, seconds; shaded area indicates differences under the just-noticeable difference threshold of $40 \mathrm{~ms}$

Each dot represents a single speaker's duration difference in seconds between their utterances of each word in the pair. In the dam/damn pair, for instance, speaker F03 produced damn with a 
vowel duration of $262 \mathrm{~ms}$ and dam with a duration of $161 \mathrm{~ms}$. On the other hand, F06 and M05 each uttered dam with durations noticeably longer than their damn tokens. The rest of the participants' durations were well under the $40 \mathrm{~ms}$ 'just-noticeable difference' threshold suggested by Lehiste (1970) for speech sounds of this length, denoted by the shading within $\pm 40 \mathrm{~ms}$.

3.2. DuRATIONS BY FOLLOWING SEGMENT. After finding no consistently differentiated minimal pairs (Section 3.1), it is necessary to explore other ways of quantifying variation in the length of /æ/. Figure 2 displays overall average duration of /æ/ by following segment; bars are colored from darkest to lightest based on how much the consonant type, averaged over the whole subject pool, encourages overall vowel lengthening. /nd/ is plotted separately from both the nasal group and the nasal + voiceless stop group, as monosyllabic words cannot end with $/ \mathrm{mb} /$ clusters (lamb has lost its final stop) or $/ \mathrm{ng}$ / (as this cluster tends to be reduced to $/ \mathrm{y} /$ word-finally). To avoid token-level pseudoreduplication in the data, within-word means were calculated for each subject's bad, glad, mad, and sad, and each word was only counted once per speaker (Winter 2011).

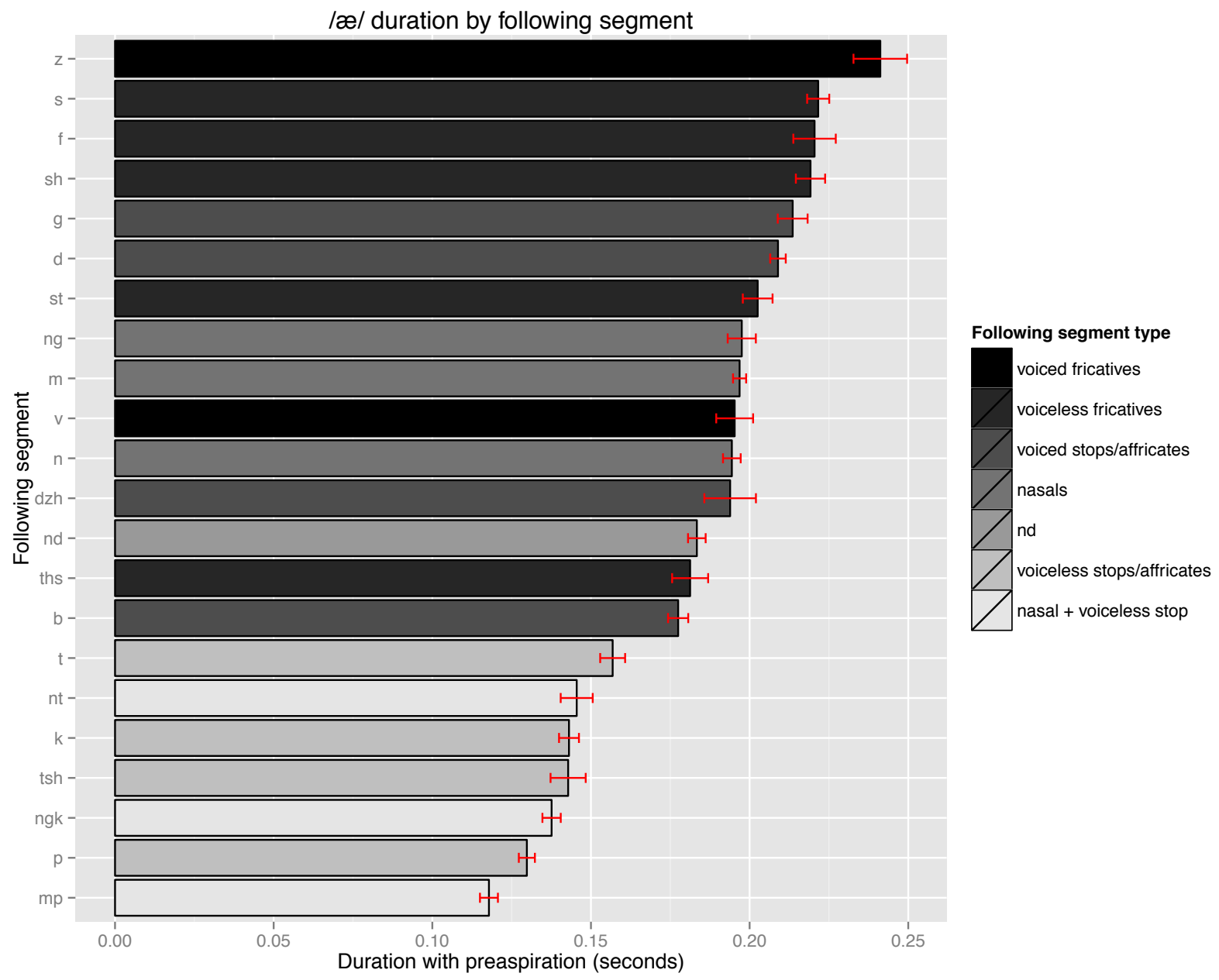

Figure 2. /æ/ duration (including breathy voice and preaspiration) by following segment, averaged over all speakers 
Voicing, unsurprisingly, significantly affects duration $\left(\chi^{2}(1)=55.262, p<0.001\right)$. Voiceless segments - among which $/ \mathrm{mp} /, / \mathrm{nt} /$, and $/ \mathrm{nk} /$ were included in order to differentiate them from $/ \mathrm{nd} /$ with a voiced stop - lowered duration by about $0.050 \mathrm{~s} \pm 0.005$ std. err. $(\mathrm{p}<0.001)$.

Manner of articulation of the following consonant also affects vowel duration in the overall model $\left(\chi^{2}(5)=80.162, \mathrm{p}<0.0001\right)$. Pairwise tests between manners reveal several significant differences between fricatives and other manners of articulation, but not between other sets of manners: vowels before fricatives are on average $0.064 \mathrm{~s} \pm 0.012 \mathrm{std}$. err. longer than before stops $(p<0.0001)$; fricatives also lengthened more than nasal + stop clusters by $.084 \mathrm{~s} \pm 0.012 \mathrm{std}$. err. $(\mathrm{p}<0.0001)$; more than nasals by $0.067 \mathrm{~s} \pm 0.014$ std. err. $(\mathrm{p}=0.0001)$; and more than affricates by $0.076 \mathrm{~s} \pm 0.018$ std. err. $(\mathrm{p}=0.0004)$.

Within groupings of segment type based on manner of articulation and voicing, place of articulation appears to make a difference in lengthening. Average /æ/ measurements before /g/ and $/ \mathrm{d} /$ are very close to each other, but significantly longer than those before $/ \mathrm{b} /$. Voiceless stops show a slightly different pattern, with /æ/ before / $\mathrm{t} /$ longer than before $/ \mathrm{k} /$, which in turn is longer than before $/ \mathrm{p} /$. This pattern is repeated within the nasal + voiceless stop class: /nt/ lengthens more than $/ \mathrm{yk} /$, which itself lengthens more than $/ \mathrm{mp} /$. There seems to be no overall effect of place of articulation within the nasals, with $/ \mathrm{y} /, / \mathrm{n} /$, and $/ \mathrm{m} /$ showing no identifiable differences in length. These differences based on place of articulation are not reflected in the overall linear mixed effects model $\left(\chi^{2}(5)=0, p=1\right)$, possibly because for different manners - which were not entered as random effects, but rather as independent fixed effects - place of articulation may have differing effects. Teasing apart these differences requires a more in-depth look at how individuals behaved with regard to place of articulation as well as word-specifically.

\subsection{VOWEL LENGTHS OF INDIVIDUAL WORDS FOR EACH SPEAKER (POSTVOCALIC ORAL STOPS).}

Figures 3-5 present the vowel lengths of individual words for each speaker and are organized so as to compare durations across monosyllabic words containing final postvocalic oral stops. Words ending in /d/ have been implicated in previous descriptions of secondary /æ/-lengthening, and Section 3.2 found similar overall lengthening of $/ \mathrm{g} / \mathrm{but}$ not $/ \mathrm{b} /$; such words are therefore analyzed alongside their voiceless counterparts. Since for most words only one token per speaker was elicited, any mistakes or stumbles a speaker may have made were excluded.

Wells (1982) identified final /d/ as the primary environment for lexically-specified duration contrasts. Since $\mathrm{bad}$, glad, $\mathrm{mad}$, and sad were spoken up to four times by each participant, these words are plotted on Figure 3 with bars representing the standard error of the measurements. Subjects differ in both their within-/d/ range of durations and the words that appear to be especially long or short. For instance, subjects F02, F11, and M01 are very consistent in their durations, and as such seem to have no split in this environment. Others, such as F01, F13, and M05, exhibit large by-word variation in the lengths of their pre-/d/ vowels. For subjects with relatively large variation in this environment, $\mathrm{bad}$, $\mathrm{mad}$, and sad tend to be especially long, with glad slightly shorter. In addition, add is often longer than others, even surpassing the adjectives for some subjects (F05, F15); this could be an effect of not having an onset consonant, which may encourage compensatory lengthening of the vowel (Abercrombie 1967).

It is also important to consider words ending with $/ \mathrm{t} / \mathrm{in}$ comparison to /d/ words. Several subjects, such as F08, F09, F11, F13, and M04, produced a considerably longer vowel in that than in other/t/-final words, which otherwise display minimal variation (cf. Jones 1972 [1918]). Figure 3 therefore plots that separately, with other/t/ words averaged together and standard error shown. It can be observed that F01, for instance, appears to produce that with a duration more in keeping with her /d/ adjectives, while $p a d$, $c a d$, and $C A D$ pattern closer to the other/t/ words. 
For M04, cad falls within the /t/ standard error, while that is even longer than the mean of bad tokens; other/d/ words lie in-between these extremes.

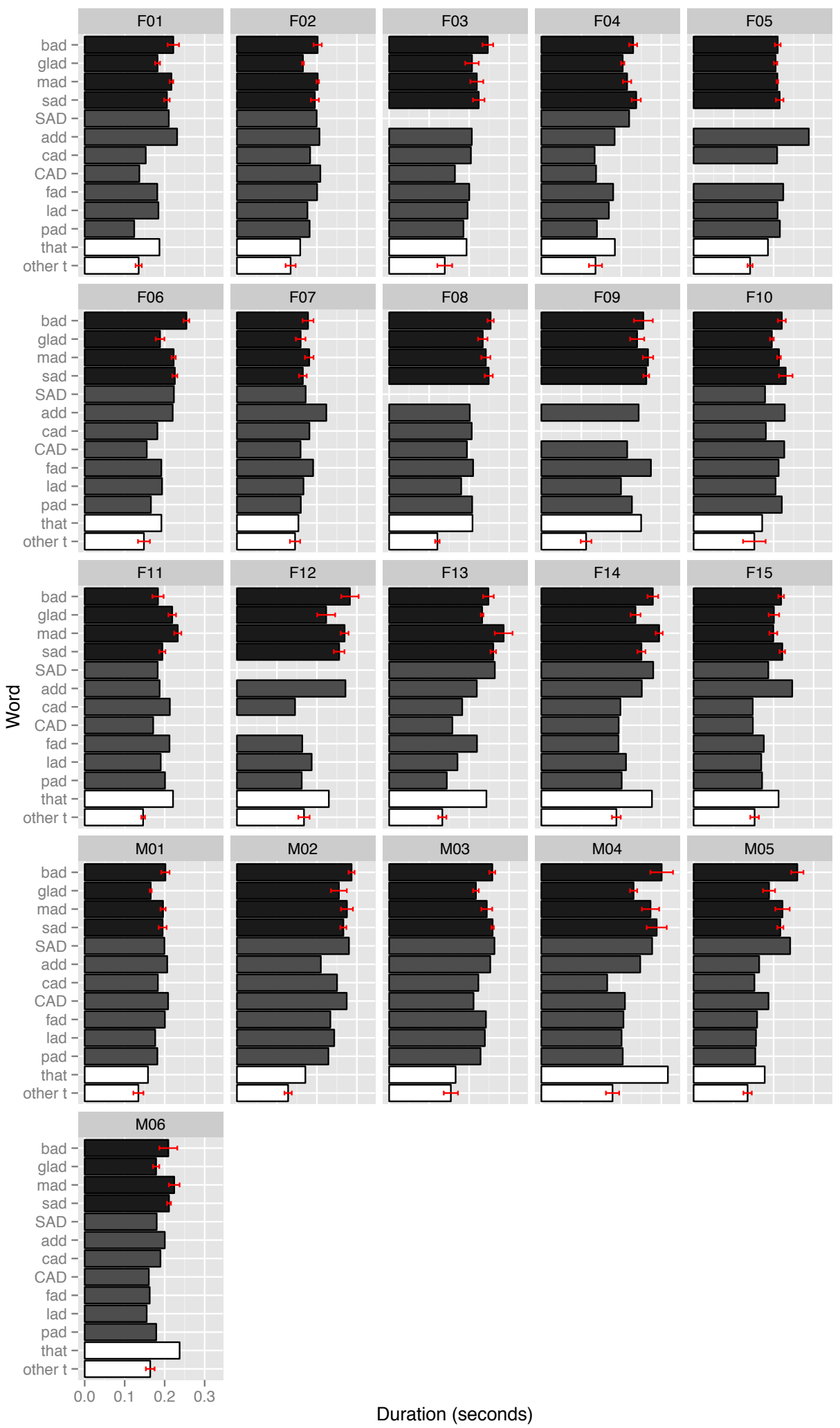

Figure 3. Vowel lengths in words ending in oral alveolar stops, seconds 


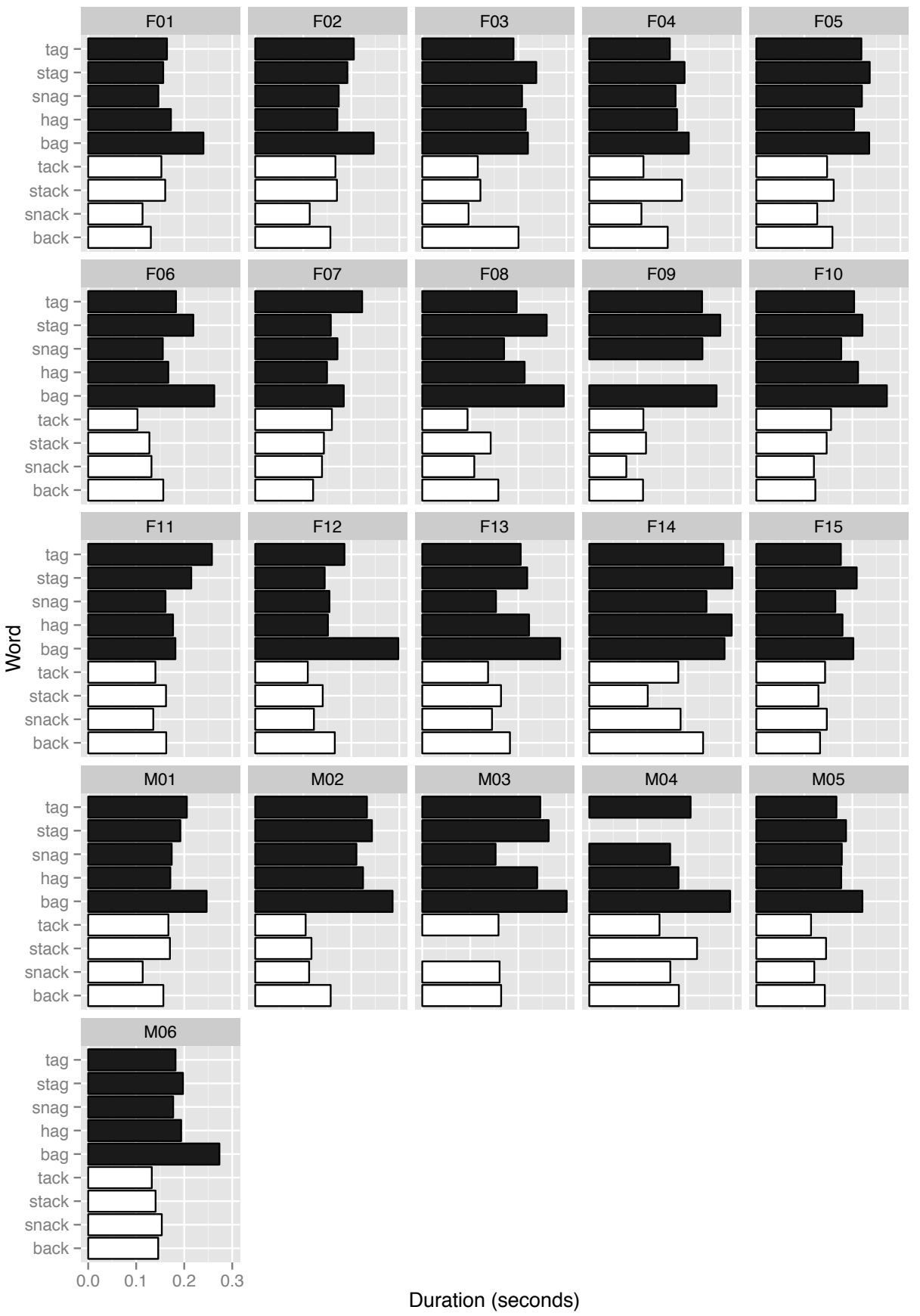

Figure 4. Vowel lengths in words ending in oral velar stops, seconds

Considering words ending in $/ \mathrm{g} /$ or $/ \mathrm{k} /$ (Figure 4 ), it is again seen that subjects pattern quite independently from each other. While many lengthen bag much more than other $/ \mathrm{g} /$ words (e.g. F01, F02, F06, F10, F12, M04, M06), others do not: F11, for instance, lengthens tag over others. Though F03 does not have a split within her /g/ words, her back lengthens considerably (cf. Jones 1972 [1918]), patterning with the $/ \mathrm{g} /$ words rather than the $/ \mathrm{k} /$ words. 


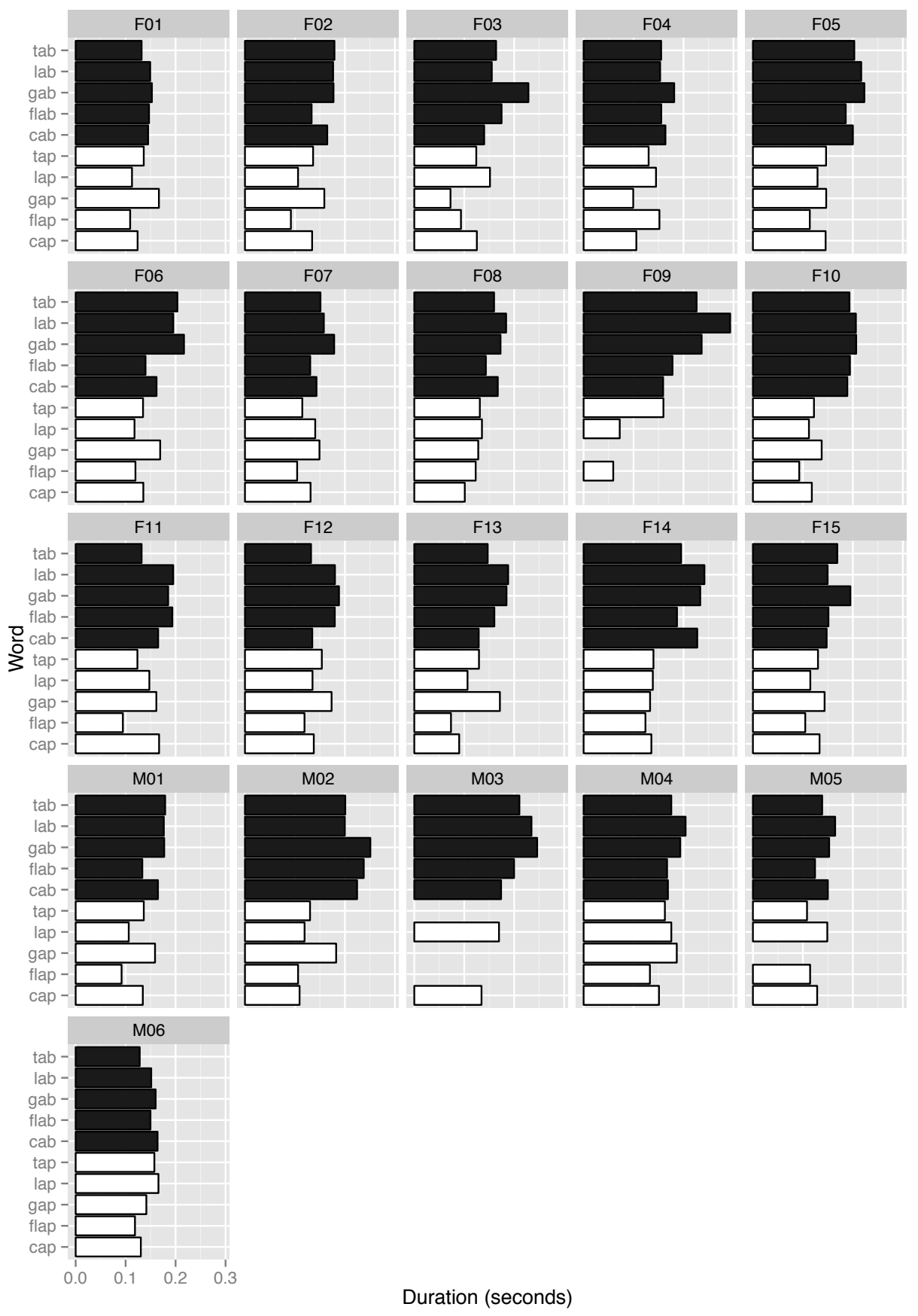

Figure 5. Vowel lengths in words ending in oral labial stops, seconds

Considering the bilabial stops (Figure 5), few patterns are apparent. F09 has an especially long $l a b$, but this is not noted in other speakers. Overall, there are less extreme differences between $/ \mathrm{p} /$ and $/ \mathrm{b} /$ than there are between the other pairs of stops.

4. Discussion. Intuitively categorizing one's own /æ/ words as 'long' or 'short', as SSBEspeaking linguists have done in previous descriptions (Section 1), is deceptively simple. Evaluating this putative dichotomy using acoustic measurements turns out to be much more difficult, especially given the lack of consistent minimal pairs (Section 3.1) and often chaotic results at the 
token level (Section 3.3). Instead of trying to reduce this allophony to a binary categorical distinction, it is fruitful to consider hierarchies of following segments that may inhibit or encourage lengthening.

4.1. COMPARISON WITH DEFAULT COARTICULATORY EFFECTS. The observation that there is a difference in length, but not quality, between the vowels in pairs such as bat and bad reflects a wellestablished articulatory universal: the voicing of the consonant following /æ/, as with all vowels, has an intrinsic effect on its duration. All else being equal, the vowel before a voiced consonant is longer than before its voiceless counterpart (Peterson \& Lehiste 1960). In American English, Peterson and Lehiste (1960) found an approximately 2:3 duration ratio of vowels before voiceless consonants compared with vowels before voiced consonants; vowels before nasal consonants tend to be somewhere in-between. In addition, following fricatives tend to lengthen vowels more than stops; this holds for short vowels, long vowels, and diphthongs. Thus, coarticulatory factors based on features of the following segment account for lengthening along the following approximate hierarchy (with voiced stops about equal to voiceless fricatives in encouraging lengthening):

voiced fricatives $>$ nasals $>$ voiced stops/affr. $\approx$ voiceless fricatives $>$ voiceless stops/affr.

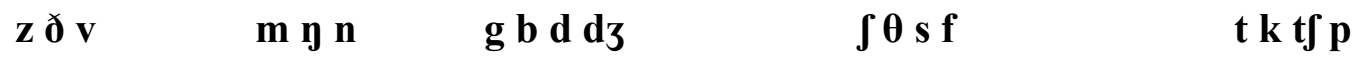

In the present experiment (see Figure 2), the set of monosyllabic words including preaspiration as a part of the vowel measurement yields the general hierarchy (voiced fricatives excluded):

voiceless fric. $\geq$ voiced stops/aff. $\geq$ nasals $>$ voiceless stops/aff. $\geq$ nasal + voiceless stops

Figure 6 presents Peterson and Lehiste's (1960:702) hierarchy, which serves as a baseline of expected vowel length based on the voicing and manner and place of articulation of the coda consonant, juxtaposing it with the lengthening hierarchy observed in the present data (excluding clusters).

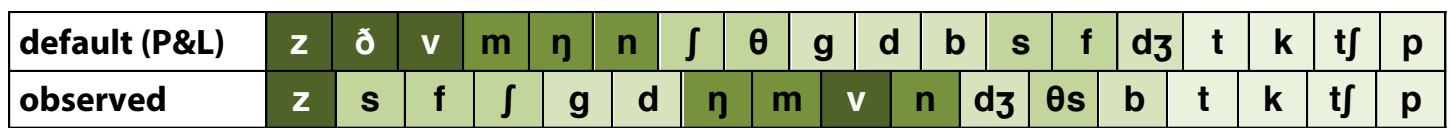

Figure 6. Peterson and Lehiste's (1960) hierarchy of coarticulatory lengthening environments (top), lengthening hierarchy observed in this study (bottom); both are colored based on the general (default) hierarchy

As for the variance between the observed lengths of $/ \mathrm{z} /$ and $/ \mathrm{v} /$ (see also Figure 2), Harris (1989) has pointed out that it may be wise to exclude tautosyllabic voiced fricatives from consideration in /æ/-lengthening because they tend to occur either in typically unstressed contexts (have, has, as) or in words coined recently (jazz). Indeed, in this experiment, only one monosyllable ending in /z/ (jazz) and one monosyllable ending in / $/$ / (chav) were targeted; / $/$ does not appear word-finally in any common /æ/ words in SSBE. The relative positions of $/ \mathrm{z} / \mathrm{and} / \mathrm{v} /$ in the hierarchy should therefore be taken with a grain of salt. At the other end of the spectrum, the observed lengths of voiceless stops/affricates matched exactly as expected, with /p/-final words having the shortest $/ \mathfrak{x} /$ durations, followed by $/ \mathrm{t} / \mathrm{f} / \mathrm{k} /$, and $/ \mathrm{t} /$.

The high position of the voiceless fricative series in the observed lengthening hierarchy was unexpected on articulatory grounds, but not unexplainable: a large degree of breathy voice after the modal section of the vowel as well as preaspiration leading into the voiceless fricative was 
observed in monosyllabic words. This dataset considers these durations part of the vowel, but future work will reexamine this data with a closer eye to the distinction between breathy vowel voice and presapiration (cf. Hejná 2015); more work is needed to fully explore the phonetic realization, phonological patterning, and vowel lengthening role of this phenomenon. It must also be noted that only one monosyllabic/æ/ word in SSBE contains coda $/ \theta /$, and that is maths. The coda consonant cluster may shorten the preceding vowel, and thus the $/ \theta \mathrm{s} /$ results are not directly comparable to singleton /s/, / $/$, and /f/.

The most striking finding from Figures 2 and 6 are the relative locations of the oral and nasal stops in the hierarchy; /g/ and /d/ lengthen more than any of the nasal environments, while /b/ behaves as expected and is below the nasals on the hierarchy. Regardless of whether there exists consistent between-word, within-/d/ or within-/g/ /æ/ duration variation (Figures 3 and 4), the fact that /b/ words do not seem to participate in lengthening beyond expected coarticulatory factors indicates that in the $/ \mathrm{g} /$ and $/ \mathrm{d} /$ environments, secondary /æ/-lengthening is a learned rather than phonetic-coarticulatory phenomenon.

4.2. COMPARISON WITH TRAP-BATH SPLIT PATTERNS. From a historical point of view, secondary /æ/-lengthening looks much like what are believed to have been the initial stages of primary /æ/lengthening. As outlined in Section 1, some words containing the Early Modern English low short vowel /a/, indeed the progenitor of the TRAP class now implicated in secondary /æ/lengthening, began to lengthen to /a:/ around the $17^{\text {th }}$ century, depending on the post-tonic consonant. Wells (1982:233) describes this split as "the ossification of a half completed sound change, which seems to have come to a stop well before completing its lexical diffusion through the vocabulary." This creates a situation in which, for instance, pass is now in the RP/SSBE BATH class, while mass still has the short vowel of TRAP.

This split, however, evolved differently in other dialects of English. The many primary /æ/lengthening patterns observed today attest to its various possible outcomes and represent different stages of development from gradient allophony to full-blown phonemic split. In the North of England, to begin with, no split ever occurred, and the PALM class remains unaugmented by lengthened arrivals from the TRAP class. English-speaking settlers in North America brought over a long Early Modern English /a:/ allophone from the South at a very early stage in primary /æ/lengthening; this long vowel raised along the front of the vowel space in most North American varieties rather than backing and rounding as in Southern England (Labov 1981). In traditional New York City English (NYCE), the relationship between TRAP and BATH has become phonologized as a lexical rule (or even possibly a phonemic split); a similar rule operates in Philadelphia (Ferguson 1972; Harris 1989; Labov 2007). NYCE, for instance, has minimal pairs such as can

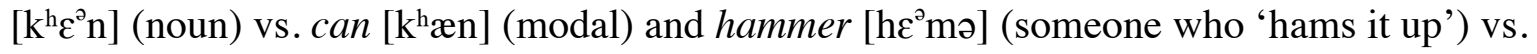
hammer [hæmə] (tool). Exemplifying another lengthening pattern, dialects spoken in American cities around the Great Lakes have resolved the complex rule system of NYCE by lengthening $/ æ /$ in all environments. This wholesale lengthening (along with variable raising) of historical short-/æ/ is believed to be the trigger behind the Northern Cities Shift (NCS), a major rearrangement involving nearly the entire short vowel system.

Labov (1971:427) proposed a "rigorous demonstration of a dialect continuum" through the comparison of primary /æ/-lengthening patterns in the American Mid-Atlantic states in a "temporal and spatial matrix" like the one in Figure 7. Along with Harris $(1986,1989)$, he argues that for American dialects, lengthening (and/or raising) in any particular phonological environment is dependent on the possibility of lengthening in other environments further down a hierarchy. Harris (1989: 48) states that "broadly speaking (ignoring place-of-articulation details), the 
implicational hierarchy is (ordered from most to least favourable): voiceless fricatives $>$ nasals $>$ voiced oral non-continuants $>$ voiceless stops." The top row of Figure 7 shows a lengthening hierarchy based on Harris' (1989) hierarchy, but is shaded from dark to light green as in Figure 6, based on Peterson and Lehiste's (1960) measurements of final consonant effects on vowel lengthening.

\begin{tabular}{l|c|c|c|c|c|c|c|c|c|c|c|c|c|c|c|c|c} 
& $\mathbf{f}$ & $\boldsymbol{\theta}$ & $\mathbf{s}$ & $\mathbf{m}$ & $\mathbf{n}$ & $\mathbf{d}$ & $\mathbf{d} 3$ & $\mathbf{b}$ & $\mathbf{g}$ & $\mathbf{J}$ & $\mathbf{v}$ & $\mathbf{z}$ & $\mathbf{\eta}$ & $\mathbf{p}$ & $\mathbf{t}$ & $\mathbf{t} \boldsymbol{\mathbf { k }}$ \\
\hline Northern Cities Shift & & & & & & & & & & & & & & & & & \\
\hline NYC & & & & & & & & & & & & & & & & & \\
\hline Philadelphia & & & & & & & & & & & & & & & & & \\
\hline RP (Jones) & & & & \pm & \pm & \pm & & & \pm & & & & & & \pm & & \pm \\
\hline RP (Wells) & & & & + & & \pm & & & & & & + & & & & & \\
\hline RP (Fudge) & - & - & - & \pm & \pm & \pm & \pm & \pm & \pm & - & \pm & \pm & - & - & - & - & - \\
\hline General American & & & & & & & & & & & & & & & & & \\
\hline North England & & & & & & & & & & & & & & & & &
\end{tabular}

Figure 7. Lengthening hierarchy of primary /æ/-lengthening (color shading, with dark blue indicating consistent lengthening environment, light blue inconsistent or lexically specified lengthening, and red no phonological lengthening); previous descriptions of secondary /æ/lengthening overlaid (+lengthening environment, \pm lexical lengthening, -no lengthening)

The NCS system has the lengthened phoneme in all environments - in Figure 7, these are shaded dark blue. The NYC system, however, allows raising in environments more favorable than $/ \mathrm{v} /$ and $/ \mathrm{z} /$ (/f, $\theta, \mathrm{s}, \mathrm{m}, \mathrm{n}, \mathrm{d}, \mathrm{d}_{3}, \mathrm{~b}, \mathrm{~g}, \mathrm{~J} /$, once allowing for the complex rules governing raising environments), but never before $/ \mathrm{p}, \mathrm{t}, \mathrm{k} / ; \mathrm{v} /$ and $/ \mathrm{z} /$ words seem to not pattern regularly, and are shown in light blue (Labov 2007). In Philadelphia, by contrast, /m, n, f, $\theta$, s/ are consistent raising environments, but $\mathrm{mad}$, bad, and glad are the only pre-/d/ words to raise, as opposed to short sad. In the case of General American English (displayed for comparison), regular, phonetically-conditioned allophonic variation has emerged between approximately short [æ] and long $\left[\varepsilon^{2}\right]$ reflexes of a single phoneme, with the long reflex occurring before nasal consonants. The primary /æ/-lengthening pattern of RP and SSBE fits broadly into this matrix below the NYC and Philadelphia systems; the lexically-specific lengthening environments for BATH are before voiceless fricatives excluding $/ \mathrm{S} /$, and coda clusters beginning with a nasal, excluding $/ \mathrm{y} /$.

The secondary /æ/-lengthening patterns introduced in Section 1 can be overlaid on this colored matrix (Figure 7). Since the three authorities on RP cited here do not always agree on the environments in which they declare TRAP words to lengthen, they are each represented by a row. Environments claimed to contain both 'long' and 'short' words are marked ' \pm ' as opposed to environments that never lengthen (-) and always do (+). It is striking that the most favorable environment for the historical lengthening of /æ/ according to Harris (1989), voiceless fricatives, has not been implicated in any previous secondary /æ/-lengthening descriptions; Fudge (1977) explicitly rules out these environments as allowing lengthening, and neither of the others make any mention of $/ \mathrm{f}, \theta, \mathrm{s}, \mathrm{J} /$. The present study's finding of longer vowel durations before voiceless fricatives, though not mentioned in any previous descriptions of secondary /æe/-lengthening, may indicate a further historical similarity between the two phenomena.

The comparability of this experiment's gradient hierarchy of lengthening behavior (Figure 6) with hierarchies constructed using the binary categorizations of primary /æa/-lengthening and purported secondary /æ/-lengthening cannot be taken for granted. However, Harris (1989) has 
suggested that /æ/-lengthening phenomena first arise through the phonologization of 'intrinsic' and therefore gradient phonetic contrasts conditioned by co-articulatory constraints across consonantal contexts. In this way, very minor durational differences due to operations in phonetic spellout may at some point phonologize as rule-governed allophonic variation; after phonologizing, they have the potential to become rules operating at the lexical level (as he argues is the case in NYC) or fully phonemicize as a split (as in RP/SSBE).

Harris' $(1986,1989)$ hierarchy, however, clearly contradicts Peterson and Lehiste's (1960) cross-vowel co-articulatory lengthening hierarchy. Though he sees these 'intrinsic' phonetic contrasts as 'natural' in that they can be related to substantive aspects of articulatory dynamics, Harris (1986) is also careful to state that it is not the resulting rules themselves that are 'natural', but rather the historical changes of which they are synchronic reflexes. For the voiceless fricative environment, the observation of breathiness/preaspiration in the present data may offer a 'natural' explanation for a synchronic or diachronic tendency toward lengthening that is otherwise captured neither by Peterson and Lehiste's (1960) hierarchy nor by previous /æ/-lengthening reports. On the other hand, it remains unexplained why certain words with coda $/ \mathrm{g} /$ and $/ \mathrm{d} /$, but not $/ \mathrm{b} /$, would be lengthening environments - whether for all words or only for a certain few. This exhibits an interesting parallel with Philadelphia's primary/æ/-lengthening system, in which coda $/ \mathrm{b} /$ and $/ \mathrm{g} /$ are not lengthening environments, but $/ \mathrm{d} /$ is for several words.

5. Conclusion. Lengthening of low short vowel classes has occurred numerous times in the history of English: the FACE vowel lengthened and subsequently shifted as part of the $15^{\text {th }}-16^{\text {th }}$ century Great Vowel Shift, and BATH lengthened and shifted in the TRAP-BATH split, or primary $/ \mathfrak{x} /$ lengthening, of many Modern English dialects. The observation that $/ \mathfrak{x} /$ is noticeably longer in a subset of words or environments in SSBE is therefore of interest to the study of the recurrent diachronic patterns apparent in the history of the English low vowel space (cf. Gburek 1985; Labov 2007). Fudge (1977:55) details his own intuitions of this secondary /æ/-lengthening, but concludes that "what general principles there may be can only be established by detailed study of a large number of idiolects," acknowledging that an experimental study of this phenomenon would require both the preparation of a body of data targeting appropriate words and a group of informants speaking a similar variety of English. This study answers his call for further research, reporting the first experimental acoustic analysis of secondary /æ//lengthening in SSBE.

Primary /æa/-lengthening patterns can be compared along "a recurrent pattern of implicational weighting based primarily on values for voicing and manner of articulation" governing their diachronic evolution (Harris 1989:48). Applying this approach to this study's results demonstrates parallels with and divergences from both Peterson \& Lehiste's (1960) general coarticulatory vowel lengthening hierarchy and previously established /æ/-lengthening hierarchies.

The observed lengthening heirarchy's promotion of voiceless fricatives in particular (when breathy voice/preaspiration is counted in the duration of the vowel) may reflect a development in post-primary /æ/-lengthening RP/SSBE that is common enough to have occurred twice independently. Supporting this theory are observations of CLOTH-lengthening, another common process by which dialects that already have a lengthened TRAP allophone begin to also lengthen/raise certain historically short-/p/ words. In this case, the leading environments also seem to be voiceless fricatives and nasals (such as lengthened NYC long, coffee, boss) (Harris 1986, Labov 1981).

Another possibility is that similarities between the primary and secondary /æ/-lengthening environments are due to a common history, with secondary lengthening representing a linguistic 
'residue' from the TRAP-BATH split. If, as argued by Wells (1982), the split was at some point a quantity difference which only later developed a difference in quality, it is conceivable that some words or environments have continued to generate a liminal /æ:/ while others fully changed over to the /a:/ class of BATH.

Trained linguists who speak SSBE natively have pinpointed specific words that they believe to have a 'long' /æ/, but this investigation finds no evidence of minimal pairs distinguished by duration alone and inconclusive evidence of word-specific lengthening within monosyllabic words ending in oral stops. However, the observation that final $/ \mathrm{g} /$ and $/ \mathrm{d} /$ encourage lengthening more than expected by default coarticulatory factors (as opposed to $/ \mathrm{b} /$ ) may be a function of previous linguists' perceptual ability to, first, intuitively account for 'inherent' lengthening by unconscious reference to some 'natural' hierarchy, and, second, recognize deviations from this norm as being somehow out of place and therefore abnormally long. In this way, gradient duration allophony purely due to 'natural' phonetic factors are not consciously noted by speakers or listeners, since they can 'normalize' for this perceptually; it's only when durational differences, even if still gradient, cease to follow a hierarchy that people are used to and can reliably normalize against that words begin to sound comparatively 'long'.

\section{References}

Abercrombie, D. 1967. Elements of General Phonetics. Edinburgh: Edinburgh University Press. Boersma, P. \& D. Weenink. 2015. Praat: doing phonetics by computer [Computer program]. Versions 5.4.06 and 5.4.07. http://www.praat.org/.

Ferguson, C. A. 1972. Short 'a' in Philadelphia English. In M. E. Smith (ed.) Studies in Linguistics in Honor of George L. Trager. 259-274. The Hague: Mouton.

Fudge, E. 1977. Long and short [ae] in one Southern British speaker's English. Journal of the International Phonetic Association 7(2). 55-65.

Gburek, H. 1985. The Vowel /a:/ in English. In J. Fisiak (ed.) Papers from the $6^{\text {th }}$ Internatioanl Conference on Historical Linguistics. 139-148. Amsterdam: John Benjamins.

Harris, J. 1986. Phonetic constraints on sociolinguistic variation. Sheffield Working Papers in Language and Linguistics 3. 120-43.

Harris, J. 1989. Towards a lexical analysis of sound change in progress. Journal of Linguistics 25(1). 35-56.

Hejná, M. 2015. Pre-aspiration in Welsh English. Ph.D. Dissertation. University of Manchester.

Jones, D. J. 1972 [1918]. An Outline of English Phonetics, Ninth Edition. Cambridge: W. Heffer \& Sons.

Labov, W. 1971. Methodology. In W. O. Dingwall (ed.) A Survey of Linguistic Science. College Park, MD: Linguistics Program, University of Maryland.

Labov, W. 1981. Resolving the Neogrammarian Controversy. Language 57(2). 267-308.

Labov, W. 2007. Transmission and Diffusion. Language 83(2). 344-387. http://dx.doi.org/10.1353/lan.2007.0082.

Lehiste, I. 1970. Suprasegmentals. Cambridge, MA: MIT Press.

Peterson, G. E. \& I. Lehiste. 1960. Duration of syllable nuclei in English. Journal of the Acoustical Society of America 32. 693-703.

Wells, J. C. 1982. Accents of English (Vols. 1-3). Cambridge: Cambridge University Press.

Winter, B. 2011. Pseudoreplication in phonetic research. In Proceedings of the International Congress of Phonetic Science. 2137-2140. Hong Kong. 